\title{
BREVE HISTÓRICO SOBRE O DIREITO DE FAMÍLIA NOS ÚLTIMOS 100 ANOS
}

\author{
Silvio Rodrigues \\ Professor Catedrático aposentado da Faculdade de Direito da USP
}

\begin{abstract}
Resumo:
\end{abstract}
$\mathrm{O}$ artigo analisa preliminarmente a legislação civil brasileira anterior ao Código Civil. Trata, a seguir, do Código Civil e do Direito de Família nele inserido, no que concerne ao casamento, à família e à filiação.

Passa então a analisar a evolução do Direito de Família anterior a 1988 , com a Lei n. $4.737 / 42$, art. $1^{\circ} \mathrm{e}$ seu aperfeiçoamento na Lei n. $883 / 49$, depois a Lei n. 4.121/62, conhecida como Estatuto da Mulher Casada e a Lei n. 6.515/77, a Lei do Divórcio.

Finaliza discutindo o Direito de Família dentro da Constituição de 1988 , em especial a perda de relevância do casamento no quadro da família.

\section{Abstract:}

The article begins by analyzing Brazilian legislation prior to the Código Civil (Civil Code). It deals next with the Civil Code and with Family Law in it, with the parts concerning marriage, family and filiation.

It analyzes then the evolution of Family Law before 1988, with the Law \# 4.737/42 section 1st and its improvement in Law \# 4.121/62, known as The Married Woman Act and Law \# 6.515/77, the Divorce Law.

It ends with a discussion of Family Law in the Constitution of 1988 , with a special focus on the loss of relevance of marriage in the frame of the family.

1. Honrado pelo convite de colaborar na edição especial do centenário da Revista da Faculdade de Direito, cogitei de cuidar de alguns aspectos da evolução do Direito de Familia brasileiro neste período, ou seja, neste século iniciado com a fundação da revista e que se encerra nesta data. Dada a extensão do tema e a necessidade de ser breve, pareceu-me conveniente dividir a matéria em duas partes: a primeira seria mais uma notícia dos principais contornos do Direito de Família a partir de 1890, data da lei sobre o casamento civil até o advento da Constituição de 1988; e a segunda se incumbiria de análise um pouco mais profunda das principais modificações trazidas por essa Constituição, dentro do nosso sistema familiar. 


\section{DO DIREITO ANTERIOR}

2. $\mathrm{O}$ art. 1.807 do C.C. mostra o cipoal que era a legislação civil brasileira até o advento daquela codificação. Com efeito, ao revogar as Ordenações, Alvarás, Leis, Decretos, Resoluções, Usos e Costumes, tal dispositivo revela que todas essas normas disciplinaram, de uma ou de outra maneira, o Direito Civil brasileiro. Isso sem contar a consolidação de Teixeira de Freitas e a compilação de Carlos de Carvalho.

3. A primeira importante lei da nova República é o Decreto n. 181, de 24 de janeiro de 1890, a respeito do casamento civil. Ela vai servir de base para a primeira parte do livro de Direito de Família do C.C. de 1916.

4. Ainda neste período precedente ao Código, mister realçar a importância (principalmente no campo sucessório) da Lei Feliciano Pena, Decreto n. 1.839, de 31 de dezembro de 1907.

5. Pelo menos duas importantes modificações trouxe a Lei Feliciano Pena, ambas melhorando a sorte da mulher dentro do Direito das Sucessões. A primeira foi a promoção do cônjuge sobrevivente na ordem de evocação hereditária, pois passou a herdar antes dos colaterais. Com efeito, no Direito das Ordenanças o cônjuge sobrevivente só era chamado a suceder se não houvesse descendentes, ascendentes e colaterais até décimo grau. Transcrevo, mais pela curiosidade que desperta, o parágrafo inicial do Título 94 , do Livro 49 das Ordenações:

"Falecendo o homem casado abintestado, e não tendo parentes até o décimo grao contado segundo o Direito Civil, que seus bens deva herdar, e ficando sua mulher viva, a qual juntamente com ele estava e vivia em casa teúda e manteúda, como mulher com seu marido, ela será sua universal herdeira.

E pela mesma maneira será o marido herdeiro da mulher, com que estava em casa manteúda, como marido com sua mulher e ela primeiro falecer sem herdeiro até o dito décimo grao". 
6. A segunda modificação importante trazida por essa lei foi a possibilidade de clausular a legítima do herdeiro necessário, disposição que foi gerar o art. 1.723 do C.C..

\section{II - O CÓDIGO CIVIL E O DIREITO DE FAMÍLIA}

7. O livro de Direito de Familia do C.C. dedica 149 de seus 304 artigos ao casamento, ou seja, quase a metade dos seus dispositivos são consagrados ao matrimônio, desde as formalidades preliminares à sua celebração até as regras sobre a sua dissolução.

8. De um certo modo poder-se-ia dizer que o casamento era o elemento estrutural no Direito de Familia no Brasil, na forma por que o disciplinou o Código de 1916. Aliás, esse pensamento perdurou de maneira nítida entre nós, pois, a partir da Constituição de 1934 (a primeira que além de cuidar dos problemas políticos, se ocupa, também, dos sociais) se encontra sempre o preceito constitucional dizendo que a familia, constituída pelo casamento de vínculo indissolúvel, está sobre a proteção especial do Estado (Constituição de 1934, art. 144, Constituição de 1946, art. 163, Constituição de 1969, Emenda Constitucional n. 1, art. 175).

9. A familia de que cuida o legislador de 1916 é a tradicional, inspirada no privilégio da varonia, pois o art. 233 do C.C. declara que o homem é o chefe da sociedade conjugal, limita bastante os direitos da mulher casada, que inclusive é vista como relativamente incapaz quanto a certos atos e a maneira de os exercer (art. $6^{\circ}$ ).

10. Cuidarei, logo mais, da evolução desses direitos. Todavia, para acentuar essa posição tradicionalista e conservadora do C.C. em favor da família legítima, desejo mostrar como ele discrimina contra a familia ilegítima, principalmente no que se refere ao concubinato e à filiação havida fora do casamento.

11. O legislador de 1916 praticamente ignora a familia ilegítima e as raras menções que faz ao concubinato (C.C. arts. 248, IV, 1.177 e 1.719, III, etc.) o faz apenas com o propósito de proteger a família legítima e nunca como 
reconhecedoras de uma situação de fato, digna de qualquer amparo. Talvez a única referência à mancebia, feita pelo C.C., sem total hostilidade a tal situação de fato, seja a do art. 363, I, do C.C., que permite ao investigante da paternidade a vitória na demanda, se provar que ao tempo de sua concepção sua mãe estava concubinada com o pretendido pai. Nesse caso entende o legislador que o conceito de concubinato presume a fidelidade da mulher ao seu companheiro e por isso presume, juristantum, que o filho por ela havido, foi engendrado pelo seu companheiro. Nos demais casos, há sempre uma hostilidade para com a ligação entre homem e mulher fora do tálamo conjugal.

12. Em matéria de filiação, embora o C.C. trate com menos rigor o filho natural, o faz com grande perversidade em relação ao espúrio, ao proclamar em seu art. 358 que os filhos incestuosos e os adulterinos não podem ser reconhecidos. Ora, como é sabido, o reconhecimento espontâneo ou forçado é que estabelece o parentesco entre o filho ilegítimo e seus pretensos progenitores. Se a lei proíbe o reconhecimento, esse parentesco não se constitui; desse modo e segundo a legislação de 1916, o filho adulterino, por não poder ser reconhecido, não herda de seu progenitor adúltero, não tem direito a alimentos, não está sob o pátrio poder, não tem direito a usar o apelido do pai, enfim, é um estranho em relação ao homem que o engendrou. Repito: o bastardo espúrio é pouco mais que um pária. Inescondível, portanto, a discriminação contra a familia nascida fora do casamento.

\section{III - PRINCIPAIS LEIS SOBRE A FAMÍLIA, ANTERIORES A 1988}

13. Essa posição rigorosa do C.C. foi sendo abandonada paulatinamente no curso dos anos subseqüentes por uma legislação mais humana e menos conservadora. Analisemos algumas dessas leis, para examinar a evolução do Direito de Família e a situação desta até as vésperas da Constituição de 1988. Examinaremos, em primeiro lugar, a posição do filho espúrio, acentuando que a matéria sofreu intensa pressão em virtude da multiplicação dos filhos de desquitados, que, por longo tempo, foram tidos como adulterinos e, por conseguinte, insuscetíveis de serem reconhecidos. 
14. O primeiro passo na solução do problema foi dado com a promulgação da Lei n. 4.737/42, cujo art. $1^{\circ}$ determina que o filho havido fora do matrimônio poderia, depois do desquite, ser reconhecido espontânea ou forçadamente.

15. A controvérsia provocada por esse diploma fez com que ele viesse a ser aperfeiçoado pela Lei n. $883 / 49$ cujo dispositivo inicial declara:

"Art. $1^{o}$ - Dissolvida a sociedade conjugal será permitido a qualquer dos cônjuges o reconhecimento do filho havido fora do matrimônio e, ao filho, a ação para que se lhe declare filiação".

16. Assim, a nova lei permitiu o reconhecimento voluntário ou forçado do adulterino, quer a sociedade conjugal de que participava seu progenitor houvesse se dissolvido por desquite, quer por morte de um dos cônjuges. A dissolução da sociedade conjugal passou a ser o único pressuposto para o reconhecimento. Tal exigência se estribava na idéia de que o reconhecimento do adulterino, na vigência da sociedade conjugal, constituía ofensa intolerável ao outro cônjuge, capaz de provocar a ruína do casamento. Dissolvida, entretanto, a sociedade conjugal pela morte ou pelo desquite, não havia mais razão nenhuma para se respeitar a sensibilidade do cônjuge falecido ou desquitado, não persistindo razão para impedir o reconhecimento do adulterino. Quero sublinhar que a idéia de preservação do casamento continua sendo a grande preocupação do legislador.

17. Embora a Lei de 1949 se apresentasse como uma Lei Áurea para os adulterinos (ela não abrangia os incestuosos), tal diploma, não obstante, continha várias restrições ao seu direito, a principal das quais era de receberem, na sucessão de seu progenitor adúltero, somente a metade do que coubesse a seus irmãos legítimos.

18. Durante quase trinta anos a Lei n. 883/49 remanesceu praticamente intocada. Somente a Lei do Divórcio (Lei n. 6.515, de 26 de dezembro de 1977) veio ampliar o direito do adulterino, ao proclamar reconhecida igualdade de direito à sucessão, qualquer que fosse a natureza da filiação. 
Esse dispositivo abriu direito sucessório ao filho incestuoso e igualou a quota sucessória dos espúrios, a do filho legítimo. Teria o dispositivo abrangido os adotivos? Cuidarei disso logo mais, quando tratar da Constituição de 1988.

19. A segunda importante lei a chacoalhar a estrutura tradicional do então vigente Direito de Família brasileiro foi o Estatuto da Mulher Casada, Lei n. 4.121, de 17 de agosto de 1962. Essa lei procurou, dentro do possível, equiparar a mulher ao homem dentro do casamento, reduzindo muitas das restrições que o legislador anterior lhe impunha. Assim, por exemplo, e entre outras vantagens, tirou-a do rol dos incapazes. Suprimiu várias limitações que eram impostas pelo art. 242 do C.C., deu-lhe a titularidade do pátrio poder que ela, até então, desfrutava supletivamente e a manteve nessa titularidade, quando, após a viuvez, se remaridava.

20. Finalmente a Lei do Divórcio de 1977, a que já me referi, que além de trazer profunda modificação representada pela admissão do divórcio a vínculo entre nós, trouxe consideráveis alterações em outros capítulos de Direito de Família, quer em relação à pessoa dos filhos, quer quanto a alimentos e principalmente em dezenas de dispositivos referidos nas disposições transitórias. Era esse, um breve apanhado, o panorama do Direito de Família brasileiro, quando a Constituição de 5 de outubro de 1988, através de quatro ou cinco dispositivos, trouxe mudanças estruturais naquele capítulo do nosso ordenamento jurídico.

\section{IV - A CONSTITUIÇÃO E O DIREITO DE FAMÍLIA}

21. O primeiro fato que chama a atenção na Carta de 1988 é sua menor consideração pelo casamento dentro do quadro da família. Com efeito, divergindo das constituições anteriores (vide supra n. 8) a Constituição vigente não repete o que dizem aquelas (que a familia é constituída pelo casamento); apenas afirma que a família está sob a especial proteção da lei. Com efeito, a Constituição nesse capítulo só se refere ao casamento para dizer que ele é civil, é gratuito e que a lei deve facilitar a conversão da união estável em casamento. 
22. Essa menor consideração do legislador constituinte em relação ao casamento conduziu, como conseqüência, a uma outra posição em matéria de divórcio.

23. Como todos os estudiosos sabem, a Lei do Divórcio só foi admitida entre nós após grandes lutas e poder-se-ia mesmo dizer que o foi sorrateiramente, pois dependeu de emenda constitucional, editada quando, transitoriamente, se alterou o quonum necessário para mudança na Carta Magna. Ademais a Lei só foi aprovada com grandes restrições. De modo que a nossa legislação sobre o divórcio, disciplinado pela Lei n. 6.515, de 28 de dezembro de 1977, que se enfileirava entre as mais tímidas do mundo, tornou-se, com as modificações subseqüentes, uma das mais arrojadas do planeta.

24.

Com efeito, a Constituição de 1988, com seu apontado menosprezo pelo casamento, colocou a nossa legislação divorcista entre as mais audazes, pois declarando que o casamento civil poderia ser dissolvido mediante comprovada separação de fato por mais de dois anos, escancarou as portas para o divórcio. Pois a mera separação de fato, por aquele período, permitia a qualquer dos cônjuges reclamar a dissolução do matrimônio, independente da prova de culpa e independente da anuência do consorte.

25. Esta posição do legislador, facilitando o divórcio, se mostra ainda mais veemente com a promulgação da Lei n. 8.408, de 15 de fevereiro de 1992, que dispõe:

"Art. $5^{\circ}$

$\S 1^{o}$ A separação judicial pode também ser pedida se um dos cônjuges provar a ruptura da vida em comum há mais de um ano consecutivo e impossibilidade de sua reconstituiçāo".

26. Paralelamente a essa relativa desconsideração pelo casamento, a Constituição revelou o propósito de dar um status ao concubinato ao proclamar que, para efeito da proteção do Estado, é reconhecida a união, estável, entre o homem e a mulher, como entidade familiar. É verdade que na prática e até que sobrevenha legislação ordinária a respeito, tal dispositivo não representa 
modificação maior na situação dos concubinos, até então vigente. Mas, obviamente, tal disposição reflete uma profunda alteração de atitude.

27.

O mais devastador dispositivo constitucional, a revolucionar a estrutura do Direito de Família pátrio, foi o art. 226, § 5º, da Carta de 1988, proclamando que "os direitos e deveres referentes à sociedade conjugal são exercidos igualmente pelo homem e pela mulher".

28. Como disse acima, a família do C.C. é uma família tradicional, baseada nos privilégios da varonia, onde o homem é o chefe da sociedade conjugal, conservando a mulher uma posição secundária. Já vimos, também, que essa posição melhorou, no correr dos tempos, com o Estatuto da Mulher Casada e com a Lei do Divórcio. Todavia, com a proclamação da igualdade absoluta entre os cônjuges, a Constituição sacudiu de uma vez a tradição brasileira. Vejamos alguns exemplos e examinarei, de início, a questão do nome da mulher.

29.

O C.C., em sua versão original, trazia o art. 240, que merece transcrição, não só por sua formosa redação, como por representar um considerável progresso no status da mulher casada.

'Art. 240 A mulher assume, pelo casamento, com os apelidos do marido, a condição de sua companheira, consorte e auxiliar nos encargos da família"

30. Disse que este dispositivo representava considerável progresso em relação à situação da mulher, no Direito anterior. $E$, de fato, assim é. No sistema das Ordenações (Liv. V, Tít. 36, § $1^{\circ}$ ), não pratica ato censurável aquele que castigar criado, ou discípulo, ou sua mulher ou seu filho ou seu escravo. Lafayette (Direito de Família, § 38), cuidando do poder marital, cuja necessidade reconhece, observa que a possibilidade de castigar a mulher, permitida pelas Ordenações (Liv. V, Tít. $36, \S 1^{\circ}$, e $95, \S 4^{\circ}$ ), tão repugnante à dignidade humana e à civilização moderna, foi revogada pelo Código Criminal. Mas ensina que, em virtude do poder marital, compete ao marido o "direito de exigir obediência da mulher, a qual é obrigada a moldar suas ações pela vontade dele em tudo que for honesto e justo"

A respeito, transcrevo Coelho da Rocha, que, escrevendo em meados do século XIX, diz: 
"Ao marido, como chefe da sociedade conjugal, compete o direito de exigir da mulher respeito $e$ obediência em tudo o que for lícito e honesto, donde resulta de parte desta: $1^{o}$ - a obrigação de o acompanhar (...) $2^{o}$ - a de lhe prestar os serviços $e$ trabalhos domésticos, conforme suas forças e estado. Pela faculdade, que a Ord. L. V, Tít. 36, concede ao marido, de castigar a mulher, se justifica a prática de a fazer entrar em algum recolhimento" (Ob. cit., t. 1, § 230).

Não se pode negar que o art. 240 , acima transcrito, trouxe um progresso na condição da mulher casada, pois deu-lhe a condição de consorte e companheira.

31. Mas voltemos à questão do nome. A mulher, com o casamento, assumia os apelidos de familia do marido. Não era apenas um direito mas uma obrigação. A Lei do Divórcio, no art. 50, modificou essa orientação para declarar, no parágrafo único do art. 240 do C.C., por ela criado, que a mulher podia acrescer aos seus os apelidos do marido. Portanto, em vez de um dever, a adoção do nome do marido passou a ser uma faculdade da mulher que se casava.

32. Havendo a Constituição igualado os direitos do homem e da mulher, dentro do casamento, surge um problema novo. Pode o homem adotar os apelidos de familia da mulher? Terá a mulher perdido o direito de acrescer o apelido do marido? Há que se considerar a velha tradição, ao que saiba universal, da mulher adotar o sobrenome do varão. O que acontece na prática?

33.

$\mathrm{Na}$ prática poderá haver acordo, por ocasião do casamento, mantendo-se o velho hábito. Mas, pergunta-se: pode o oficial do Registro Civil se recusar a acrescentar no assento o novo nome da mulher? É alarmante essa preocupação do legislador de interferir em assunto de interesse exclusivamente doméstico e uma prova dessa despropositada inferência se encontra no parágrafo único do art. 25 da Lei do Divórcio na redação que lhe deu a Lei n. 8.408, de 13 de fevereiro de 1992, verbis: 
"Parágrafo único. $A$ sentença de conversão determinará que a mulher volte a usar o nome que tinha antes de contrair matrimônio, só conservando o nome de família do ex-marido se a alteração prevista neste artigo acarretar:..."

34. Note-se que a lei é portadora de uma ordem. Diz que a sentença determinará que a mulher volte a usar o nome de solteira. Por que? Qual o interesse? Se marido e mulher estão de acordo em que ela prossiga usando o apelido do marido por que impedi-lo? Trata-se de violência absolutamente injustificada.

35. Uma devastação brutal, no respeitante aos efeitos do casamento, ocorreu com o art. 233 do C.C. Dizia esse dispositivo em sua versão original:

"Art. 233 - O marido é o chefe da sociedade conjugal. Compete-lhe:

I. A representação legal da família.

II. A administração dos bens comuns $e$ dos particulares da mulher, que ao marido competir administrar, em virtude do regime matrimonial adotado, ou do pacto ante-nupcial (arts. 178, § 9o, I; 274; 289, I; e 311).

III. O direito de fixar e mudar o domicílio da família (art. 36).

IV. $O$ direito de autorizar a profissão da mulher e a sua residência fora do teto conjugal (arts. 231, II e VII; 243 a 245, II; e 247, III).

$V$. Prover à mantença da familia guardada a disposição do art. 277".

36. Como se vê é a familia na sua estrutura machista e patriarcal. Todavia, já o Estatuto da Mulher Casada (Lei n. 4.121/62) abrandou o texto. Em primeiro lugar suprimiu o n. IV, podendo portanto desde então a mulher casada exercer posição fora do lar sem anuência do consorte. Ademais abrandou a regra do caput do inciso, limitando os poderes da chefia do lar; com efeito ao dizer que 
o marido era o chefe da sociedade conjugal, a Lei de 1962 acrescentou que tal função era exercida "com a colaboração da mulher, no interesse comum do casal e dos filhos".

37. Já de há muito sustentei que tal disposição era de grande relevo e que a desobediência a seus termos provocava grave sanção. Dizia então:

"De maneira que a atividade do marido, no desempenho daquele mister, só será lícita se for exercida no interesse do casal e dos filhos, pois, caso se comprove que isso não se dá, seus atos serāo carentes de liceidade, podendo a mulher pleitear que ele decaia da chefia da sociedade conjugal, que passará, por força da sentença judicial, a ser exercida por ela".

e na nota:

"103. A solução adotada no texto entra em conflito com a regra do art. 251 do Código Civil, que a Lei de 1962 não alterou e que, taxativamente, relaciona os casos em que a mulher assume a chefia da sociedade conjugal.

Reafirmo que, no meu entender, pode o juiz determinar que a mulher assuma a chefia da sociedade conjugal, quando se apurar que o marido a está exercendo com detrimento do interesse do casal e dos filhos.

Qualquer interpretação da lei, em sentido diverso, deixaria sem sanção aquele comportamento do marido, tirando qualquer sentido à reforma que a Lei n. 4.121, de 27 de agosto de 1962, inseriu no art. 233 do Código Civil.

A solução esposada no texto atende à vontade do legislador, que circunscreveu a atividade do marido, que só pode atuar no interesse comum do casal e dos filhos" 
(Silvio Rodrigues, Direito civil, $16^{\mathrm{a}}$ ed., São Paulo, Saraiva, 1973, v. 6, n. 58).

38. Também o direito de fixar o domicilio do casal foi afetado com o Estatuto da Mulher Casada, pois ao inciso III do art. 233, se acrescentou a locução "ressalvado à mulher a possibilidade de recorrer ao juiz" Portanto, quando a fixação do domicilio da família, pelo marido, prejudicava a mulher, podia ela recorrer ao magistrado para corrigir $o$ abuso.

39. A igualdade entre os cônjuges, trazida pelo preceito constitucional, também provocou mudanças substanciais. Em primeiro, revogou o parágrafo único do art. 36, que atribuía domicilio necessário à mulher. Em segundo, deulhe direito igual ao do marido de fixar domicilio. Tanto aquela quanto este tem direitos semelhantes.

40. Isso me leva a pensar que se um dos cônjuges deixa o domicilio conjugal para ir viver alhures, não se pode dizer que abandonou o lar e sim que decidiu fixar o domicilio do casal em outro lugar. Ou, então, se abriria discussão para se estabelecer judicialmente, quem, no interesse da familia, deve fixar o domicílio daquela.

41. Vejamos agora a questão da mantença da familia referida no atual art. 233, IV, do C.C.

42. A lei (art. 233, IV, do C.C.) impunha ao marido a obrigação de manter a familia. Esta regra tradicional em nosso direito se inspirava na secular divisão do trabalho entre os cônjuges, ficando a mulher dentro de casa a cuidar dos filhos e da economia doméstica, indo o homem trabalhar fora do lar em busca de meios para sustentar os seus. De maneira que, constituindo a atividade do marido, ordinariamente, a fonte exclusiva de ganho da familia, impunha-lhe a lei a obrigação de manter a mulher e a prole.

43. $\mathrm{O}$ mandamento legal encontrava uma única exceção na hipótese de serem os cônjuges casados pelo regime de separação absoluta de bens, caso em que a mulher devia concorrer para as despesas do casal com os rendimentos de seus bens, na proporção de seu valor, relativamente aos do marido (C.C., art. 
277). Note-se que a mulher casada só concorria com o rendimento de seus bens e não com o produto de seu trabalho.

44.

A Lei n. 4.121/62, inovando, sujeitou a mulher a concorrer com seus bens, para a mantença da família, também na hipótese do art. 275 daquele Código, ou seja, quando houver contraído dívidas não autorizadas pelo marido, ou nas hipóteses em que se dispensa essa autorização.

45.

Ademais, a mesma Lei n. 4.121/62, em seu art. $2^{q}$, determinou que a mulher casada contribuirá para as despesas de família, com a renda dos seus bens, como se o regime fosse de separação (C.C., art. 277), se os bens comuns forem insuficientes para atendê-las.

46. Portanto, no direito até ontem vigente, a regra geral, em matéria de mantença da família, era no sentido de incumbir ao marido tal encargo, com as exceções dos arts. 277 e 275 do C.C. e do art. $2^{\circ}$ da Lei n. 4.121, de 27 de agosto de 1962.

47.

Ainda no regime anterior à reforma constitucional de 1988, escrevia eu:

"Todavia, da mesma forma que a evolução dos costumes tirou a mulher de dentro do lar, para conduzila a atividades remuneradas nos escritórios, nas lojas, nas fábricas, nos hospitais etc., não mais se compreende, nem se justifica, que sua colaboração na mantença da família se circunscreva às hipóteses acima referidas. A regra de 1916 dispunha para uma outra época, pois figurava a posiçāo da moça rica que se casa pelo regime da separação de bens, e que deve, naturalmente, concorrer para o sustento da família. Hoje, ao contrário, freqüentemente a mulher ganha tanto ou mais que o marido e é justo que participe do sustento da família, como de resto lhe impõe, em relação aos filhos, o inciso $I V$ do art. 231 do Código Civil" (Ob. cit., n. 62). 
48. Essa situação de absoluta igualdade foi alcançada com o dispositivo constitucional tantas vezes citado (art. 226, $\$ 5^{\circ}$ ), que diz que os direitos e deveres referentes à sociedade conjugal são exercidos igualmente pelo homem $\mathrm{e}$ pela mulher.

49. Desse modo e dentro do quadro teórico, o dever de prover à mantença da família deixou de ser apenas um encargo do varão, porque esse dever hoje incumbe também à mulher.

50. Há um problema prático da maior relevância que não pode ser olvidado, que a norma constitucional não pode esconder. É que em grande número de casos, de todas as classes da população, das mais ricas às mais carentes, o sistema antigo prevalece; ou seja, em numerosas familias ainda existe a divisão do trabalho na vida conjugal, o varão exercendo profissão fora do lar e a mulher se ocupando dos afazeres domésticos e da criação dos filhos.

51.

Aqui me parece lógico que a Constituição não poderia alterar a regra do art. 233, IV, do C.C., porque só o marido terá meios econômicos para manter a esposa e filhos, já que a mulher, por definição, não os percebe.

52.

Nesses casos figurados, que de resto são numerosíssimos no momento, creio que a regra antiga continua em vigor e que ao marido compete prover a manutenção da família. Dois problemas podem ser encarados, em tal hipótese. De um lado a obrigação de manter os filhos e de outro o de manter a esposa que, por conveniência da familia, não exerce profissão, nem tem fonte de renda.

53. O dever de o marido manter os filhos decorre do parentesco. Além de ser-lhe imposto, neste caso, pelo dispositivo em análise, ou seja, pelos arts. 231, IV, e 396 e ss. do C.C..

54. $\quad \mathrm{O}$ problema subseqüente é o de saber se a mulher que se desquita tem direito a receber alimentos de seu ex-marido, em face à igualdade estabelecida na Constituição.

55. É tradicional do Direito brasileiro reconhecer à mulher que se desquita o direito de receber pensão do marido, isso com base na já apontada divisão de tarefas. $\mathrm{Na}$ maioria dos casos, a mulher não tem economia própria, 
pois dedicou-se a maior parte do tempo ao serviço não-remunerado do lar. Assim, não raro nas separações amigáveis, encontra-se cláusula fixando uma pensão a ela; aliás, o Código de Processo, no seu art. 1.121, IV, contempla a hipótese dessa pensão ser fixada, se a mulher "não possuir bens suficientes para se manter".

56

Ainda tradicional no Direito brasileiro é a regra segundo a qual a mulher inocente e pobre, no desquite litigioso, tenba direito a uma pensão. Estará em vigor esta regra? Se no desquite litigioso o homem for inocente e pobre, terá ele direito a uma pensão?

57. Outro artigo em matéria de alimentos, que foi alterado pelo princípio da igualdade, é o de n. 224 do C.C. Tal disposição, na separação de corpos requerida por um dos cônjuges, permitia à mulher requerer alimentos provisionais "que lhes serão arbitrados na forma da lei". Tal preceito tinha razão de ser e continuará a prevalecer, quando os bens comuns estiverem sendo administrados pelo marido. Isto porque esses alimentos ad liten são concedidos para prover um litigante de recursos, quando estes se encontram em mãos do outro. Assim, o melhor entendimento desse dispositivo legal seria aquele em que, decretada a separação de corpos, quando qualquer dos cônjuges a tenha requerido, o outro cônjuge poderá pedir ao juiz que lhe arbitre alimentos provisionais, que lhe deverão ser pagos pelo primeiro, se este estiver administrando o patrimônio do casal.

Haveria alguns outros aspectos do Direito de Família brasileiro que foram praticamente revogados, senão profundamente modificados pela regra que estabeleceu a igualdade entre o homem e a mulher dentro do matrimônio. Não vou tratar de todos estes aspectos, porque na maioria dos casos eles são óbvios.

Para finalizar, quero acentuar a igualdade de todos os filhos, qualquer que seja a sua natureza, trazida pelo $\S 6^{0}$ do art. 227 da nova Constituição.

Aí se diz que os filhos, havidos ou não da relação do casamento ou mesmo por adoção, terão direitos e qualificações iguais, ficando proibidas quaisquer designações discriminatórias relativas à filiação. 
Através deste preceito os filhos adotivos passaram para um plano de absoluta igualdade, havendo a regra constitucional revogado todas as disposições discriminatórias contra o adotivo, inclusive o art. 377 do C.C.. 